\title{
DESENVOLVIMENTO DE PROCESSO PARA REUSO DA ÁGUA PRODUZIDA NA INDÚSTRIA DE PETRÓLEO
}

\author{
F. M. RONQUIM ${ }^{1}$, R. HELENO ${ }^{1}$, M. H. TOGNON ${ }^{1}$, M. M. SECKLER ${ }^{1}$ \\ ${ }^{1}$ Universidade de São Paulo, Departamento de Engenharia Química \\ E-mail para contato: flavia.mronquim@yahoo.com.br
}

\begin{abstract}
RESUMO - Com uma gama de poluentes, a água produzida proveniente dos poços de petróleo requer tratamento para descarte em emissários, reuso ou reinjeção em poços. Ademais, no futuro, com mais restrições ambientais, novos processos de tratamento serão necessários. No presente estudo, desenvolveu-se uma alternativa para tratamento e reuso da água produzida, buscando-se um desempenho na eletrodiálise reversa (EDR) que não seja comprometido por incrustações em membranas. Para tanto, foram estudados processos de pré-tratamento aplicáveis à água de alimentação da EDR, como filtração para redução do teor de óleos e graxas (TOG) e precipitação para redução de sais pouco solúveis. Embora as incrustações nas membranas de EDR pela formação de fouling oleoso e scaling por sulfato de bário $\left(\mathrm{BaSO}_{4}\right)$ representam grandes desafios para aplicação dessa tecnologia em reuso da água produzida, com o pré-tratamento aqui proposto, é possível prevenir-se de tais inconvenientes.
\end{abstract}

\section{INTRODUÇÃO}

O termo água produzida designa água proveniente dos poços de exploração e produção de petróleo. Constituída de uma corrente de grande volume, a água produzida geralmente representa um volume similar ao de óleo produzido. Contendo uma gama de poluentes, tais como: orgânicos (óleos dispersos ou dissolvidos), sólidos dissolvidos totais (SDT-sais), amônia, boro, e metais pesados, esta requer tratamento para descarte em emissários ou reinjeção em poços. $\mathrm{O}$ tratamento convencional para descarte consiste de métodos físicos (tratamento primário) e biológicos (tratamento secundário). No entanto, para o reuso da água produzida, seja como água industrial ou irrigação, é necessário recorrer a tratamento terciário para redução adicional de salinidade, do teor de óleos e graxas (TOG) e de sólidos dissolvidos totais (SDT). Neste caso, a etapa mais importante é a de dessalinização, a qual pode ser realizada num processo por membranas, principalmente pelas técnicas de osmose reversa ou eletrodiálise reversa (EDR) (REAHL, 2006).

Os sistemas de membrana requerem um pré-tratamento da alimentação para reduzir problemas de incrustação. A presença de óleos e graxas pode acarretar a formação de uma camada de resina oleosa que bloqueia a passagem de íons de e para os sítios de troca de iônica nas membranas, além de ocasionar obstrução severa da cama de resina e até mesmo danos 


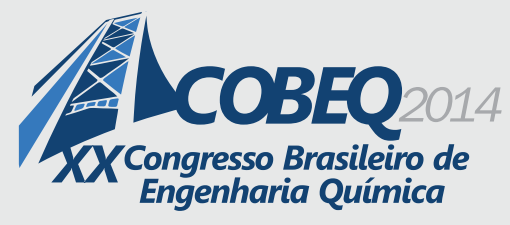

19 a 22 de outubro de 2014
Florianópolis/SC

mecânicos devido à queda de pressão através da resina incrustada. Além disso, incrustações também são formadas sobre as membranas ou outras partes do sistema por precipitação de sais de baixa solubilidade em água (como o $\left.\mathrm{BaSO}_{4}\right)$, as quais provocam obstruções e perda de eficiência. $\mathrm{Na}$ ausência de anti-incrustante, o produto iônico de $\mathrm{BaSO}_{4}$ tolerado no concentrado corresponde a 100 vezes o produto de solubilidade. Com o uso de anti-incrustante, algumas plantas operam com um produto iônico 150 vezes o produto de solubilidade (ALLISON, 2010). No entanto, nestas condições são necessárias interrupções frequentes da operação para limpeza, há um alto consumo de reagentes de limpeza e uma diminuição na vida útil das membranas. Os gastos econômicos associados a estas práticas são consideráveis, já que podem custar até 2 milhões de dólares sem contar o prejuízo com a parada de produção, enquanto que os métodos preventivos de incrustação possuem custos bem menores que os métodos de remoção (ARAI E DUARTE, 2010). No caso de descarte zero, o uso de anti-incrustantes é indesejável, pois interfere com o tratamento do concentrado a jusante da membrana.

Neste trabalho, um processo para o tratamento terciário de água produzida visando descarte zero é proposto, o qual consiste de etapas de separação de óleos e graxas e de precipitação de bário integrados à separação por membranas. A combinação destas operações é feita de tal forma a minimizar as incrustações nas membranas. Como modelo, foi estudada a presença do sulfato de bário $\left(\mathrm{BaSO}_{4}\right)$ em sistemas EDR.

\section{PROCESSO PARA REUSO DA ÁGUA PRODUZIDA}

\subsection{Filtração}

Em um sistema de tratamento típico de água produzida, os teores de sólidos suspensos totais (SST) e de óleos e graxas de origem mineral (TOG) são reduzidos de cerca de 1000-2000 $\mathrm{mg} / \mathrm{L}$ até 29-100 $\mathrm{mg} / \mathrm{L}$. Em instalações offshore (plataformas marítimas de exploração e produção de petróleo) são empregados hidrociclones, enquanto em instalações onshore (em terra firme) são comumente empregados separadores de placas corrugadas (CPI) ou separadores API. Em seguida, em ambos os processos (onshore e offshore) utilizam-se células de flotação hidráulica para atender aos requisitos de descarte em corpo receptor. (AMERICAN PETROLEUM INSTITUTE, 2014; KASHAEV E LEE, 2010).

De acordo com o Conselho Nacional do Meio Ambiente (CONAMA, 2011), o limite de descarte TOG (seja livre, emulsionado ou disperso) presentes na água produzida é de até 20 $\mathrm{mg} / \mathrm{L}$. Para atingir tal especificação, ou ainda reduzir a um padrão mais rígido como o de descarga zero, podem ser aplicados filtros de leito profundo de diversos tipos de leitos, como: areia, cascalho, antracito, casca de nozes entre outros (IGUNNU E CHEN, 2012).

Diferentes tipos de meio filtrantes para tratamento da água produzida foram avaliados, tais como: areia de sílica, carvão antracito, pedregulho, casca de nozes inglesas, casca de nozes negra (black walnut shell), e casca de nozes pecan. O material que apresentou os melhores resultados foi a casca de nozes negra, com elevado oil wetting, baixo fluxo para fluidização, baixa perda por abrasão e elevado coeficiente de retenção de óleo entre 0,25 - 0,4 g óleo/g leito, contra 0,1 - 
0,2 g óleo/g leito para filtros de areia. Além disso, o fluxo nominal em função da perda de carga para o filtro casca de nozes varia de $25-39 \mathrm{~m}^{3} / \mathrm{m}^{2} / \mathrm{h}$, enquanto que, para a mesma perda de carga, o fluxo para o filtro de areia e filtro com carvão antracito variam de $16-28 \mathrm{~m}^{3} / \mathrm{m}^{2} / \mathrm{h}$ (RAWLINS E ERICKSON, 2010).

\subsection{Dessalinização com membranas}

Os sistemas mais aplicados para dessalinização da água produzida incluem Osmose Reversa (OR) e Eletrodiálise Reversa (EDR).

A Eletrodiálise Reversa (EDR) é uma tecnologia madura de dessalinização. Este processo engloba a separação de íons dissolvidos da água de alimentação através de membranas de troca iônica em série, contendo sítios funcionais eletricamente carregados e arranjados em modo alternado entre o ânodo e o cátodo, para remoção das substâncias com cargas. As membranas carregadas positivamente permitem exclusivamente a passagem de ânions. De forma similar, para as membranas carregadas negativamente permitem a passagem de cátions. Periodicamente a polaridade é revertida para minimizar a incrustação (IGUNNU E CHEN, 2012).

A Osmose Reversa (OR) é um processo por membranas dirigido por pressão, de modo a promover a separação de componentes iônicos ou dissolvidos, sendo usualmente empregado em dessalinização. A pressão osmótica da solução de alimentação é suprimida ao se aplicar uma pressão hidráulica que força o permeado (água limpa) a se difundir através de uma membrana densa, não-porosa (IGUNNU E CHEN, 2012).

Segundo Reahl (2006), os valores limites de óleos e graxas (TOG) na alimentação dos sistemas OR e EDR, são respectivamente zero e 1ppm. Considerando-se ainda diversos parâmetros limites de alimentação menos toleráveis na RO que na EDR, conclui-se que os sistemas EDR são mais versáteis (REAHL, 2006).

\subsection{Precipitação}

A alta concentração de íons $\mathrm{Ba}^{2+}$ em águas produzidas exige, normalmente, a adição de anti-incrustante para prevenção de deposição de incrustações em sistemas de EDR. Tal aditivo é, porém, indesejado pelo alto custo e por dificultar cristalização no caso de se desejar aproveitar também o rejeito da EDR (concentrado), como no descarte zero, visto que este inibe o desempenho da etapa de cristalização evaporativa a jusante. Deste modo, propõe-se a implantação de uma etapa de precipitação de Bário para evitar a adição de anti-incrustante.

A precipitação do íon bário contido na água de alimentação, se dará por reação química com sulfato de sódio $\left(\mathrm{Na}_{2} \mathrm{SO}_{4}\right)$ produzindo sulfato de bário $\left(\mathrm{BaSO}_{4}\right)$ através da reação (1).

$\mathrm{Ba}^{2+}+\mathrm{Na}_{2} \mathrm{SO}_{4(\mathrm{~s})}+2 \mathrm{H}_{2} \mathrm{O}_{(\mathrm{l})} \rightarrow \mathrm{BaSO}_{4(\mathrm{~s})}+2 \mathrm{Na}^{+}+2 \mathrm{OH}^{-}+2 \mathrm{H}^{+}$

O sulfato de bário sólido forma-se quando o produto iônico dos íons bário e sulfato em 
solução, $\mathrm{PI}=\mathrm{C}_{\mathrm{Ba}} \cdot \mathrm{C}_{\mathrm{SO} 4}$, excede o produto de solubilidade $\mathrm{K}_{\mathrm{ps}}=1,07.10^{-10} \mathrm{M}^{2}$. A extensão da precipitação pode ser controlada pela quantidade de sulfato de sódio adicionada, pois um excesso deste reagente aumenta a supersaturação $S_{2}$ definida como $S_{2}=P I / K_{p s}$.

\subsection{0 processo}

A Figura 1 apresenta o processo de tratamento de água produzida visando o seu reuso total. Tem-se o tratamento convencional para redução de sólidos suspensos totais e TOG, buscando- se atendimento ao CONAMA resolução 430 para descarte em emissário, e o tratamento terciário para reuso da água produzida como água industrial ou irrigação. E, por fim, tem-se o tratamento por cristalização evaporativa para descarte zero.

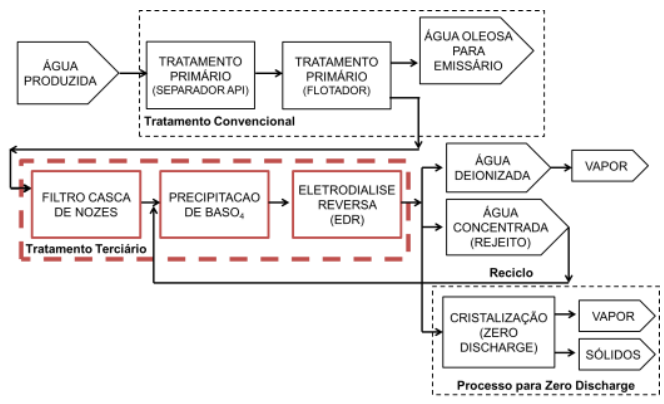

Figura 1 - Fluxograma de processo para tratamento da água produzida.

A precipitação do íon bário visa diminuir o risco de danos aos equipamentos da EDR por incrustação do sal sulfato de bário, sem necessidade de se empregar aditivos anti-incrustantes. Um fluxograma do processo é mostrado na Figura 3.

A solução de saída do filtro de nozes alimenta o precipitador, onde ocorrerá a reação (1) e, então, o sal precipitado $\mathrm{BaSO}_{4}$ é separado da água no decantador por diferença de densidade. Considerou-se que a precipitação do bário ocorre até o equilíbrio termodinâmico e que o decantador tem eficiência de $100 \%$ na remoção de sólidos.

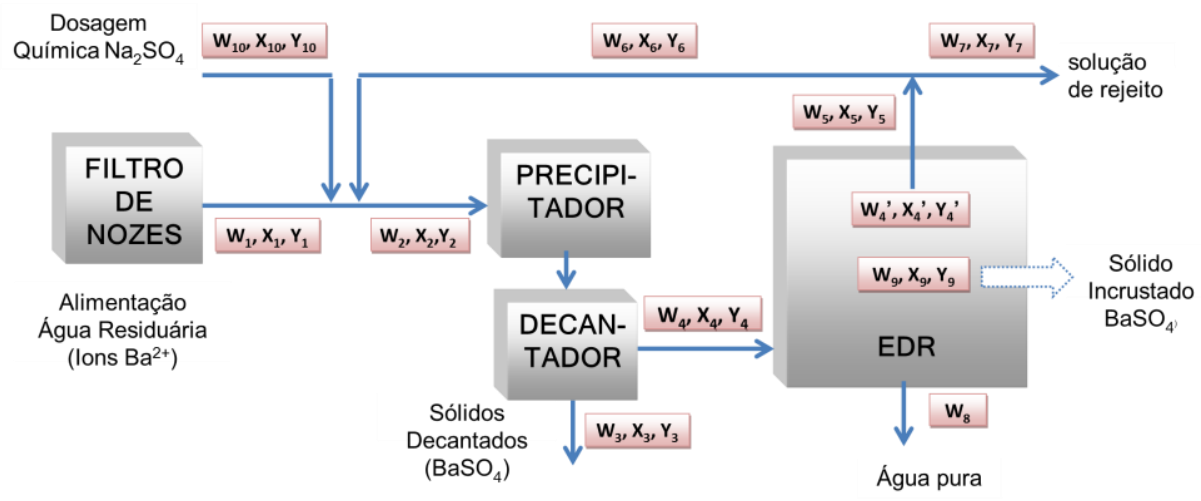

Figura 2 - Fluxograma do processo de precipitação acoplada a eletrodiálise reversa. 
Sendo que:

$\mathrm{W}_{1,2,4,5,6,7}=$ vazão $[\mathrm{kg}$ solução $/ \mathrm{s}]$

$\mathrm{W}_{3,9}=$ vazão $[\mathrm{kg}$ BaSO4$/ \mathrm{s}]$

$\mathrm{W}_{10}=$ vazão $\left[\mathrm{kg} \mathrm{Na} \mathrm{N}_{2} \mathrm{~S}_{4} / \mathrm{s}\right]$

$\mathrm{X}_{1,2,4,5,6,7}=$ concentração $\left[\mathrm{kg}_{\mathrm{Ba}}^{2+} / \mathrm{kg}_{\text {solução }}\right]$

$\mathrm{X}_{4}{ }^{\prime}=$ concentração $\left[\mathrm{kg} \mathrm{Ba}^{2+} / \mathrm{kg}_{\text {solução conc. }]}\right.$

$\mathrm{Y}_{4}{ }^{\prime}=$ concentração $\left[\mathrm{kg}\right.$ so $^{2-} / \mathrm{kg}$ solução conc. $]$

$\mathrm{Y}_{1,2,4,5,6,7}=$ concentração $\left[\mathrm{kg} \mathrm{so4}{ }^{2-} / \mathrm{kg}_{\text {solução }}\right]$

$$
\begin{aligned}
& \mathrm{W}_{8}=\text { vazão }\left[\mathrm{kg}_{\text {água }} / \mathrm{s}\right] \\
& \mathrm{W}_{4}{ }^{\prime}=\text { vazão }\left[\mathrm{kg}_{\text {solução concentrada }} / \mathrm{s}\right] \\
& \mathrm{X}_{3,9}=\text { concentração }\left[\mathrm{kg} \mathrm{Ba}^{2+} / \mathrm{kg}_{\mathrm{BaSO} 4}\right] \\
& \mathrm{X}_{10}=\text { concentração }\left[\mathrm{kg} \mathrm{Na}^{+} / \mathrm{kg} \mathrm{Na}^{2-S O 4}\right] \\
& \mathrm{Y}_{3,9}=\text { concentração }\left[\mathrm{kg} \mathrm{SO}^{2-}{ }^{2-} \mathrm{kg}_{\mathrm{BaSO} 4}\right] \\
& \mathrm{Y}_{10}=\text { concentração }\left[\mathrm{kg} \mathrm{SO}^{2-} / \mathrm{kg} \mathrm{Na} \mathrm{Ng}^{2}\right]
\end{aligned}
$$

Quando a solução entra na eletrodiálise reversa, os íons (átomos com falta ou excesso de elétrons) são atraídos pelas membranas de troca iônicas, formando uma solução $\mathrm{W}_{4}$ ' concentrada entre os sítios funcionais eletricamente carregados, enquanto água pura é recuperada. A EDR tem duas correntes de saída: uma solução diluída $\left(\mathrm{W}_{8}\right)$, considerada água pura e uma solução concentrada saturada em sulfato de bário $\left(\mathrm{W}_{5}\right)$. Na figura 2 , representou-se ainda uma terceira corrente $\left(\mathrm{W}_{9}\right)$ de sulfato de bário sólido, representativa do sólido que incrusta na membrana. Foi especificado um valor desejável de $85 \%$ de recuperação de água pura no processo, proporcionando uma solução 6,7 vezes mais concentrada que a alimentação. Por fim, foi acrescentado um reciclo equivalente a $0,3 \mathrm{Kg} / \mathrm{s}$ da solução concentrada, que representa $15 \%$ da água de alimentação do EDR, para possibilitar economia no consumo de sulfato de sódio reagente.

Foi analisado de modo quantitativo, por balanço de massa, a incrustação por $\mathrm{BaSO}_{4}$ nas membranas da EDR, conforme se realiza a precipitação prévia do sal. Para tanto, contabilizou-se, na etapa de precipitação, a retirada do íon $\mathrm{Ba}^{2+}$ da solução à medida em que se aumentava a adição do reagente sulfato de sódio, havendo deslocamento do equilíbrio para produção de sal na eq.1. As condições de entrada encontram-se na Tabela 1.

Tabela 1 - Valores característicos do sistema

\begin{tabular}{ccccc}
\hline $\begin{array}{c}{\left[\mathrm{Ba}^{2+}\right] \text { de }} \\
\text { entrada } \\
(\mathbf{m g} / \mathbf{L})\end{array}$ & $\begin{array}{c}\left.\mathbf{S O 4}^{2}{ }^{-}\right] \text {de } \\
\text { entrada } \\
(\mathbf{m g} / \mathbf{L})\end{array}$ & $\begin{array}{c}\text { Vazão de } \\
\text { alimentação } \\
\text { do } \\
\text { cristalizador } \\
\mathbf{W}_{\mathbf{2}}(\mathbf{m g} / \mathbf{s})\end{array}$ & $\begin{array}{c}\text { Reciclo } \\
(\mathbf{m g} / \mathbf{L})\end{array}$ & $\begin{array}{c}\text { Aumento da } \\
\text { concentração } \\
\text { de íons no } \\
\text { concentrado } \\
\text { da EDR }\end{array}$ \\
\hline 1,2 & 1,2 & 2000 & 300 & 6,7 vezes \\
\hline
\end{tabular}

Aplicou-se um balanço de massa 1 no cristalizador, a fim de se determinar a vazão do sólido precipitado $\mathrm{W}_{3} \mathrm{e}$ as concentrações $\mathrm{X}_{4} \mathrm{e} \mathrm{Y}_{4}$ de bário e sulfato, respectivamente, na solução . Sabendo-se que

$$
\begin{gathered}
W_{2}=W_{3}+W_{4} \\
X_{2} \cdot W_{2}=X_{3} \cdot W_{3}+X_{4} \cdot W_{4} \\
Y_{2} \cdot W_{2}=Y_{3} \cdot W_{3}+Y_{4} \cdot W_{4} W_{4}
\end{gathered}
$$


Sabe-se, ainda, que pelo produto de solubilidade dado pela equação (5) estabeleceu-se uma constante $\mathrm{k}$ :

$$
X_{4} \cdot Y_{4}=S \cdot K_{p s}=k
$$

Sendo que $S=1$ para precipitação que ocorre até a saturação e $\mathrm{K}_{\mathrm{ps} \mathrm{BaSO} 4}=1,07.10^{10}$ para $\mathrm{T}=20^{\circ} \mathrm{C}$. As equações (6) e (7) são usadas para se determinar o valor de $\mathrm{X}_{4}$ e $\mathrm{Y}_{4}$, respectivamente, a partir do $\mathrm{W}_{3}$ que será calculado através da equação (10).

$$
\begin{aligned}
& 2,3 \cdot X_{2}=X_{3} \cdot W_{3}+X_{4} \cdot\left(2,3-W_{3}\right) \\
& 2,3 \cdot Y_{2}=Y_{3} \cdot W_{3}+Y_{4} \cdot\left(2,3-W_{3}\right) \\
& 2,3 \cdot X_{2}=X_{3} \cdot W_{3}+\left(\frac{k}{Y_{4}}\right) \cdot\left(2,3-W_{3}\right) \\
& Y_{4}=\frac{k \cdot\left(2,3-W_{3}\right)^{2}}{2,3 \cdot X_{2}-W_{3} \cdot X_{3}}+W_{3} \cdot Y_{3} \\
& \text { 2,3. } Y_{2}=\frac{k \cdot\left(2,3-W_{3}\right)}{2,3 \cdot X_{2}-W_{3} \cdot X_{3}}
\end{aligned}
$$

Resolvendo-se a equação (10) de $2^{\circ}$ grau e aplicando os valores conhecidos (Tabela 1), foi determinado um valor para $\mathrm{W}_{3}$. A vazão representada por $\mathrm{W}_{3}$ encontra-se na figura 5 .

Para a precipitação no sistema EDR, realizou-se o de balanço de massa 2, sende este semelhante ao balanço de massa1, porém substituindo-se: $\mathrm{W}_{2}, \mathrm{X}_{2}$ e $\mathrm{Y}_{2}$ por $\mathrm{W}_{4}$ ', $\mathrm{X}_{4}$ ' e $\mathrm{Y}_{4}{ }^{\prime} ; \mathrm{W}_{3}$, $\mathrm{X}_{3}$ e $\mathrm{Y}_{3}$ por $\mathrm{W}_{9}, \mathrm{X}_{9}, \mathrm{Y}_{9}$, assim como $\mathrm{W}_{4}, \mathrm{X}_{4}$ e $\mathrm{Y}_{4}$ por $\mathrm{W}_{5}, \mathrm{X}_{5}$ e $\mathrm{Y}_{5}$. A vazão representada por $\mathrm{W}_{9}$ encontra-se, também, na figura 5 .

Pelo balanço de massa 1, é obtida a quantidade de sólido produzida no precipitador. Define-se a conversão de bário no precipitador $C_{c r}$ como a relação entre o bário precipitado e o bário alimentado à unidade, $C_{c r}=W_{3} X_{3} / W_{2} X_{2}$. Pelo balanço 2 , por sua vez, é obtida a quantidade de sólido produzida na EDR. Analogamente define-se a conversão de bário na EDR, $C_{m}=W_{9} X_{9} / W_{2} X_{2}$. O consumo de reagente sulfato de sódio é caracterizado pela relação $C_{s o 4}=$ $W_{10} Y_{10} / W_{2} Y_{2}$

\section{RESULTADOS}

A Figura 3 mostra que a vazão de bário precipitado no precipitador aumenta com a adição de reagente, conforme esperado. Pela Figura 4, observa-se que a conversão do bário na precipitação se aproxima de $100 \%$ rapidamente. Quando se adiciona $\mathrm{Na}_{2} \mathrm{SO}_{4}$ até uma concentração de $0,621 \mathrm{~g} / \mathrm{s}$ de $\mathrm{Na}_{2} \mathrm{SO}_{4}$ na alimentação do precipitador, consegue-se uma conversão de bário precipitado de $99,9 \%$.

Ainda na Figura 4 observa-se a concentração de íons bário e de sulfato em solução após a etapa de precipitação em função da supersaturação do sistema. $\mathrm{O}$ valor do bário dissolvido diminui progressivamente com o aumento da dosagem de sulfato. 


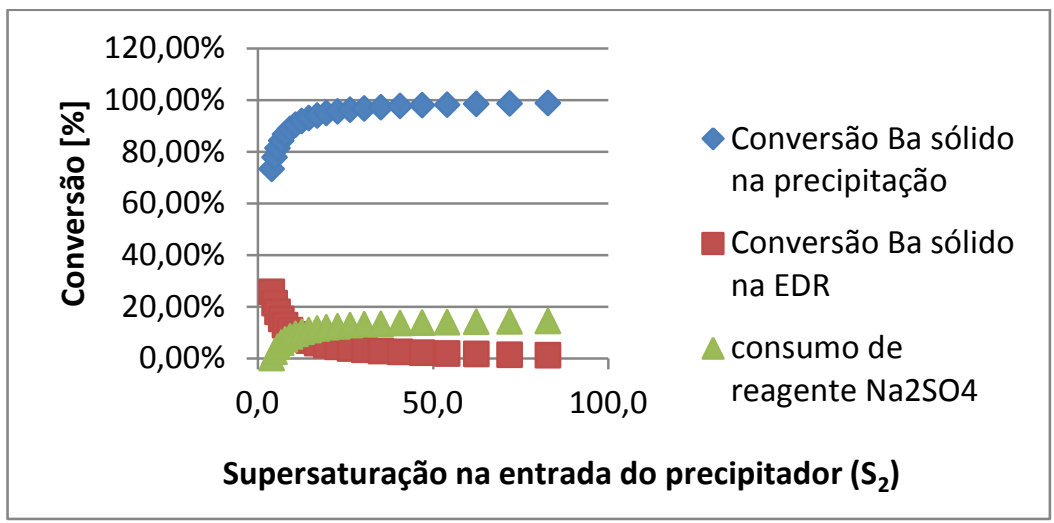

Figura 3 - Conversão do bário sólido na precipitação e na EDR e consumo de reagente $\mathrm{Na}_{2} \mathrm{SO}_{4}$
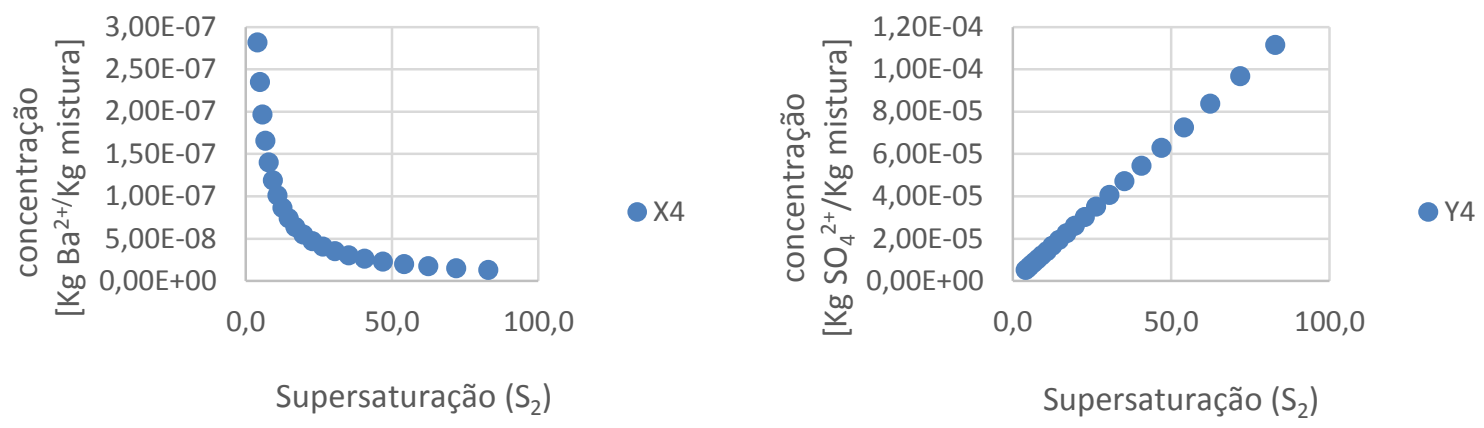

Figura 4 - Concentração do bário e do sulfato em solução após a precipitação em função da supersaturação.

Pela Figura 5 é possível observar também que a precipitação do bário na EDR é inversamente proporcional à adição de reagentes, quanto mais bário removido no precipitador, menor a vazão de sólidos produzidos na membrana.

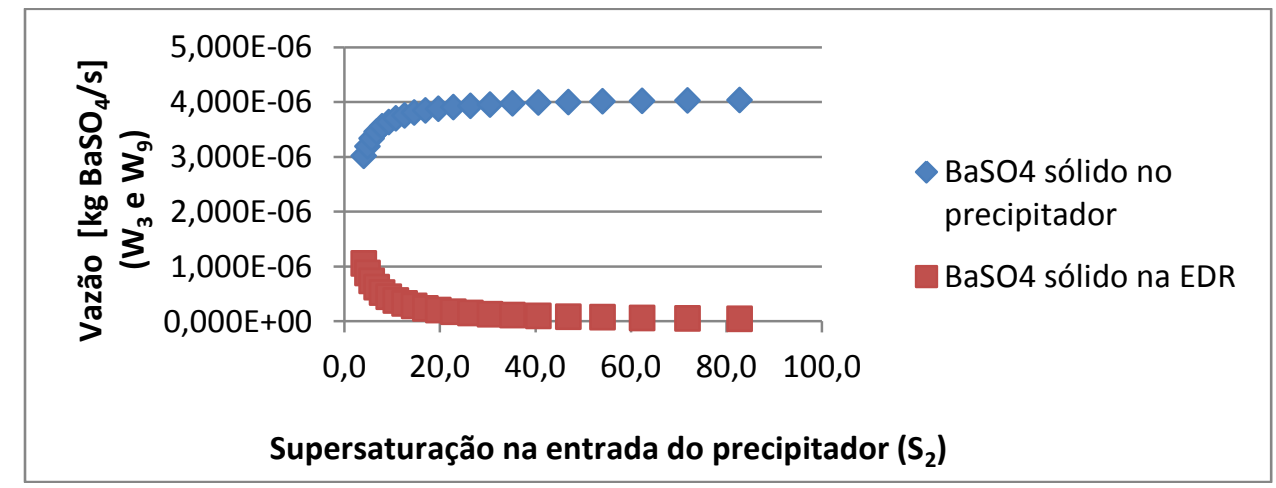

Figura 5 - Sais formados no precipitador e sais formados no sistema EDR nos balanços de massa. 


\section{CONCLUSÃO}

Foi proposta uma rota de processo para tratamento e reuso da água produzida baseado na dessalinização por eletrodiálise reversa (EDR). Devido às limitações dos sistemas de dessalinização pela incrustação nas membranas de óleos e graxas, bem como de sais pouco solúveis, foi sugerido um pré-tratamento do sistema EDR. Para a remoção de óleos e graxas foi proposto utilizar filtros casca de nozes e para a remoção de Bário a precipitação química de $\mathrm{BaSO}_{4}$ com reciclo.

A incrustação nas membranas do sistema EDR devido ao $\mathrm{BaSO}_{4}$, foi grandemente reduzida, pois foi obtida uma elevada conversão de $\mathrm{BaSO}_{4}$ na etapa de precipitação. O processo permite uma vida útil mais prolongada das membranas, eliminando a necessidade de limpezas frequentes e de anti-incrustante.

\section{REFERÊNCIAS}

ALLISON, R. P. High water recovery with electrodialysis reversal. GE power \& water : Water \& process technologies , 2010. $5 \mathrm{p}$.

AMERICAN PETROLEUM INSTITUTE. Acesso em jan. 2014. Disponível em < http://www.api.org/oil-and-natural-gas-overview>.

ARAI, A.; DUARTE, L. C. Estudo da formação de incrustações carbonáticas. Rio de Janeiro: UFRJ/Escola Politécnica, 2010.

CONAMA, Condições e Padrões de Lançamento de Efluentes, resolução 430, 13 de Maio de 2011, Art. 16. Acesso em jan. 2014. Disponível em < www.mma.conama.gov.br/conama>.

IGUNNU, E. T.; CHEN, G. Z. Produced water treatment technologies. International Journal of Low-Carbon Technologies, pp.1-21, 0, 4 jul. 2012.

KASHAEV, S.; LEE, D. W. Deep Bed Nutshell Filter Evolution . Annual Produced Water Society Seminar, 20, League City- Texas, Exterran Holdings, 2010.

RAWLINS, C. H.; ERICKSON, A. E. Characterization of deep bed filter media for oil removal from produced water. SME Annual Meeting, Phoenix, 2010. 15 p.

REAHL, E. R. Half A Century of desalination with electrodialysis. GE power \& water, 2006. 5 p. 